$\mathrm{LM}$

36,3

208 Revised 8 September 2014 Accepted 26 September 2014
Received 8 September 2014

\section{Re-skilling for the digital humanities: measuring skills, engagement, and learning}

\author{
Nisa Bakkalbasi, Damon Jaggars and Barbara Rockenbach \\ Columbia University, New York, New York, USA
}

\begin{abstract}
Purpose - The purpose of this paper is to describe an assessment design for the Developing Librarian training program. The Developing Librarian training program created by and for librarians and professional staff in the Humanities and History division is a two-year training program to acquire new skills and methodologies to support the digital humanities. The program is based on the assumption that learning must happen in context; therefore the training is project based with all participants engaged in building a digital humanities research site as a team. This approach enables participants to learn about new tools in a sustained manner that parallels the way humanities researchers are likely to use them.

Design/methodology/approach - In order to measure the success of achieving this goal, program designers defined three objectives: learn tools and methods that support the emerging research needs and trends in the humanities; create a more interesting and engaging work environment for librarians and professional staff; and engage effectively with the humanities research community across the University. Three methods/instruments were: Explicit Self-Reflections to assess what participants learned in each training unit; the Utrecht Work Engagement Scale to measure how participants feel about their work before and after the training program; and the Skill Set, Knowledge and Attitude Assessment to be administered at completion to measure the effectiveness of the training program as a whole.

Findings - At the time of writing, the Developing Librarian Project is mid-way to completion, and implementation of the assessment plan is ongoing. Based on these self-reports, there is evidence that the training program has been effective, and participants have been successful in meeting most of the learning objectives identified in the units completed. While self-assessment of knowledge and skills may have its limitations, this technique is proving adequate and efficient for achieving the program's goals. This method encourages experimentation and establishes failure as an important aspect of the learning process.
\end{abstract}

Research limitations/implications - An assessment approach such as this does not measure the impact of training and development on digital humanities research, but initiates a valuable process, highlighting skills gaps at the individual, and organizational levels. These data are important for identifying and implementing appropriate training opportunities for librarians supporting emergent research activities and for understanding what skills and professional preparation are needed for new staff recruited into the organization.

Originality/value - A successful training program should be benchmarked, evaluated in a substantive and systematic way, and improved continuously. A formal assessment plan, directly tied to clearly articulated objectives, helps assure that such a program is effectively evaluated, iteratively developed, and successfully implemented. The Developing Librarian Project provides a useful model of how an academic library can leverage assessment and evaluation processes to identify skills gaps and training needs and generate actionable data for improving staff learning.

Keywords Professional development, Assessment, Digital humanities, Re-skilling

Paper type Research paper

\section{Introduction}

Lorcan Dempsey describes the deepening engagement that many academic and research libraries are working to create for their parent institutions by producing 
"distinctive value in the research, learning and teaching workflows of their users in ways which go beyond the provision of collections" (Dempsey, 2013). Taking the idea of creating distinctive value a step farther, James G. Neal, Vice President for Information Services and University Librarian at Columbia University, suggests that academic and research libraries should "advance from the trompe l'oeil library facilities we currently maintain to new strategies for learning, intellectual, social, and collaborative spaces characterized by flexibility, adaptability, and usability [...]We need to bring the classroom and the academy into the library [...]" (Neal, 2011). For Neal, purchasing and

Re-skilling for the digital humanities

209 providing access to collections, and even providing services like library instruction is too passive. These are certainly useful activities for an academic or research library to support but not sufficient for creating a path to remaining vital to the teaching, learning, and research missions of the University. Actively supporting services closely aligned with research and teaching practices in the library through strategic collaborations with faculty and other campus partners is the way to remaining vital.

To build such a path, Columbia University Libraries/Information Services has created a series of discipline-based digital centers supporting emerging research and teaching practices in the humanities, music, sciences and engineering, and social sciences (see http://ibrary.columbia.edu/dhc.html; http://ibrary.columbia.edu/dsc.html). These centers are high-end computing environments equipped with advanced, discipline-specific software applications and peripherals, configured to support both individual and collaborative work. The digital centers offer consultation services provided by librarians, technologists, and graduate student interns, and serve as test beds for service innovation for the larger organization. Staff in the digital centers are empowered to pilot potential services in smaller, bounded environments, keeping what works, quickly discarding what does not, and testing whether or not new services can scale for the larger organization. A current example is the project in the Digital Science Center to test the viability of $3 \mathrm{D}$ printing as a production service offering (see http://3dprint.cul.columbia. edu for more information about the 3D printing pilot at the Digital Science Center).

Digital scholarship coordinator positions were created to lead service program development and outreach activities for the centers. These positions are also charged with supporting skills development for the staff who work in the centers, most of whom are traditionally trained librarians and graduate student interns. Three digital scholarship coordinator positions have been filled by recent $\mathrm{PhD}$ recipients who bring deep research and teaching expertise from the disciplines they support. That being said, most of the staff supporting the digital centers are traditionally trained librarians with widely variant levels of comfort and expertise with the emergent research tools and activities supported in the digital centers. Responding to this fact, and to a more general desire to update their skills to remain vital to the faculty and students they support, the professional staff from the Humanities and History Libraries division banded together to launch a re-skilling effort that they dubbed the Developing Librarian Project.

\section{The Developing Librarian Project}

Much is changing across the humanities research landscape. Libraries and librarians have responded in a number of creative ways to disruptions brought on by new technologies and research methodologies. Beyond providing new services utilizing new technologies, librarians have also emerged as partners and collaborators in the research process. This new partnership role for librarians illustrates that the most important change is not technological, but social: successful digital projects need 
LM

36,3

210

partners with a variety of skill sets to work closely together on teams. New skills, both technological and social, require librarians to engage in an ongoing learning process.

Librarians at Columbia University Libraries/Information Services are keen to understand and support evolving research practices. In the fall of 2012, and running in parallel with the expansion of the Digital Humanities Center, the Humanities and History $(\mathrm{H} \& \mathrm{H})$ Libraries division initiated the Developing Librarian Project, a two-year training program, with the goal of developing new skills and methodologies to support the digital humanities. Two influential publications, "Re-skilling for Research" (Auckland, 2012) published by RLUK and "Research Support Services for Scholars: History" (Schonfeld and Rutner, 2012) by Ithaka S + R provided the initial inspiration for the program. Both reports highlight skills gaps among librarians in relation to supporting emerging research needs of scholars. Using these reports as a foundation, the H\&H team created a provisional syllabus for the project, which covers those areas identified as the most significant skills gaps among staff (i.e. data management and curation, data manipulation tools used by humanities researchers, metadata schema, etc.).

The program is based on the assumption that learning happens best in context (Birchinall, 2013; Williams, 2008); therefore the training is project based with all participants engaged in creating a digital humanities research project as a team. This approach enables the team to learn about new tools in a sustained manner that parallels the way other humanities researchers are likely to use them. The program's designers built a set of practical training units and exercises for the purpose of individual and group learning and skills development.

Practical exercises are focussed on individual contributions to a common and ongoing project to document the history of Morningside Heights and its environs (the area of Manhattan where Columbia University is located) for the period 1820-1950, as the expansion of Columbia University was changing the neighborhood (see www.developinglibrarian.org for more information about the Morningside Heights digital project). The aim of the project is to produce a permanent public resource while giving the team an engaging project of manageable scope to increase the likelihood of success.

The H\&H team understands that training and skills development are no longer activities to engage in sporadically, but a continual process of learning integrated into the fabric of daily work (Gutsche, 2010). Thus, it might be more accurate to describe the project not as a training program but part of continuing professional development and engagement. The team is committed to gaining a better understanding of emergent technologies and to being partners in the research process. While the product of the Developing Librarian Project is important, the process is the most exciting, and hopefully, most lasting element of these efforts.

\section{Methodology/assessment design}

Before discussing the project's assessment methodology in detail, it is worth highlighting a few characteristics of its design. First, during initial consultations with program designers, it became apparent that an outcome-based assessment approach would be most appropriate for the project. In this context, outcome-based assessment is defined as assessing the extent to which the project has achieved its intended results.

Second, although academic libraries have historically valued training and professional development for librarians, formal assessment is rarely integrated into these activities from the outset. Most often, an informal assessment is conducted at the 
completion of a training program to gather feedback to inform future program planning. In contrast, the Developing Librarian Project implemented a model for assessment design that involves evaluation of each unit immediately following a training session, thus providing feedback to program designers before the next unit is presented to participants.

Third, this assessment design is closely linked to the learning objectives outlined in the overall program syllabus (see www.developinglibrarian.org/syllabus/ for an outline of the Developing Librarian Project syllabus), which are tied to skill set gaps discussed the digital humanities in RLUK's "Re-skilling for Research" report. The assessment component is designed to assist program designers and others interested in implementing similar training activities to learn both from the project's successes and missteps.

Finally, outcomes are measured using both self-reports and peer ratings because the training is project based with all participants engaged in creating a digital humanities research project as a team.

The development of a successful assessment design requires a clear and shared idea of what it is be achieved among a project's stakeholders. Clearly articulated objectives are the engine that drives the assessment process. Thus, the assessment design for the Developing Librarian training program stems from the mission of the Digital Humanities Center: to effectively support the current and emerging information and research-support needs of humanities scholars at Columbia University. In order to measure the success of achieving this mission, program designers defined three corresponding learning objectives in specific and measureable terms:

(1) learn tools and methods that support the emerging research needs and trends in the humanities;

(2) create a more interesting and engaging work environment for liaison librarians and other professional staff; and

(3) engage effectively with the humanities research community across the University.

Armed with clearly articulated objectives and aware that some objectives may not be easily measured, program designers developed or selected the following three instruments to measure the extent to which the project achieved its intended results:

(1) Explicit Self-Reflections to assess what participants learned in each training unit.

(2) The Utrecht Work Engagement Scale (UWES) to measure how participants feel about their work before and after the training program.

(3) The Skill Set, Knowledge and Researcher Engagement Assessment to measure the effectiveness of the training program as a whole at the completion of the project.

Table I provides details about the objective-to-measure match and timeline for data collection processes for the project.

Explicit Self-Reflections involve asking participants to name the four most important things they learned during the training unit. In this kind of reflection, participants step back from the learning process to think about what they are learning and their progress. These key takeaways are recorded immediately at the end of each unit for subsequent content analysis. Content analysis of self-reflections involves extracting key terms and concepts and mapping them to the learning objectives identified in the training syllabus. This method employs self-assessment and is based on the premise that individuals can become better learners when they engage in deliberate thought 
LM

36,3

212

about what they are learning. Self-assessment may help participants to become realistic judges of their own performance by enabling them to monitor their own learning, rather than relying on an instructor for feedback (Sambell et al., 2006).

Work engagement is measured by a brief, 17 -item, self-reported questionnaire, the UWES (Schaufeli et al., 2006). A baseline questionnaire was administered to participants at the project's launch to serve as a benchmark for comparing the impact of the training on creating a more interesting and engaging work environment for liaison librarians and other professional staff. Sharing results from the baseline questionnaire publically could create an answering bias for the follow-up questionnaire scheduled to be administered in Spring 2014; and therefore, these preliminary results are not included in the current discussion.

The Skill Set, Knowledge and Researcher Assessment (see Table II) is still under development and will be administered at the completion of the overall program, utilizing peer-assessment methods. When peer-assessment is used, ideally the method should allow learners to practice making reasonable judgments about the extent to which their peers have achieved expected outcomes (Falchikov, 2007). Therefore, this assessment will use constructive, positive terminology to describe how well any given topic has been mastered to make it easier for peers to give and receive feedback.

The skill sets and knowledge areas covered in a specific training unit will populate the assessment template for that unit. Using a four-point rating scale where $1=$ Beginning, $2=$ Developing, $3=$ Good, and $4=$ Advanced, participants will score themselves in each competency area and validate their scores by discussing them with a peer rater. The Director of H\&H Libraries will indicate which areas are essential or desirable for the effective performance of each librarian's participant's role to support humanities researchers in an evolving information environment.

\section{Findings}

At the time of writing, the Developing Librarian Project is mid-way to completion, and implementation of the assessment plan is ongoing. The current discussion reports findings for only those parts of the assessment that are complete, which includes a summary analysis of the Explicit Self-Reflections data recorded for those training units completed to date.

\section{Table I.}

Objective-to-measure match and data 3 collection timeline

\section{Objectives Instrument/method}

$1 \quad$ Explicit Self-Reflections

2 Utrecht Work Engagement Scale (UWES)

$3 \quad$ Skill Set, Knowledge and Researcher

Engagement Assessment
Data collection timeline

Fall 2012-Spring 2014

Fall 2012 (baseline) and Spring 2014 (follow-up) Spring 2014
Table II.
An example template from the Skill Set, Knowledge and Researcher Assessment instrument
Skill sets and knowledge competency areas
1 Scan and produce electronic text
2 Use of citation management software to assemble a bibliography
3 Understand author rights, copyright legislation, and intellectual property issues, and plagiarism, and to be able to advise or refer as appropriate

Self- Peer Essential/ 
Table III displays a summary of findings from self-reflections mapped to learning objectives for each unit completed. All comments for perceived knowledge and skills gained were matched against the learning outcomes of each unit. Check marks indicate learning objectives that participants believe they have mastered and cross marks indicate those areas where more work is needed.

Based on these self-reports, there is evidence that the training program has been effective, and participants have been successful in meeting most of the learning objectives identified in the units complet11ed. Looking at comments for the question "What are the four most important things you learned today?" for the completed units, content analysis shows that the majority of responses mapped to learning objectives. For example, the first learning objective of Unit 1 (Introduction to Digitization) was "Use Adobe Acrobat and Finereader to scan a document and determine when to use one or the other software." Nearly all participants who completed the unit made comments specific enough to map to the first learning objective, resulting in a check mark. Conversely, there were no comments from the participants that could be mapped to the third learning objective of Unit 1 ("Correct and clean up text in a Finereader document") to serve as evidence of skills attained in that area. While self-assessment of knowledge and skills may have its limitations, this technique is proving adequate and efficient for achieving the program's goals. This method encourages experimentation and establishes failure as an important aspect of the learning process.

\section{Conclusions}

A successful training program should be benchmarked, evaluated in a substantive and systematic way, and improved continuously. A formal assessment plan, directly tied to clearly articulated objectives, helps assure that such a program is effectively evaluated, iteratively developed, and successfully implemented. The Developing Librarian Project provides a useful model of how an academic library can leverage assessment and evaluation processes to identify skills gaps and training needs and generate actionable data for improving staff learning.

An assessment approach such as this does not measure the impact of training and development on digital humanities research but initiates a valuable process, highlighting skills gaps at both the individual and organizational levels. This data is important for identifying and implementing appropriate training opportunities for librarians supporting emergent research activities and for understanding what skills and professional preparation are needed for new staff recruited into the organization. What began, as a supporting element - the assessment of participant learning - has become a cornerstone of this project. Assessment does not sit on top of the project but

\begin{tabular}{|c|c|c|c|c|c|}
\hline \multirow[b]{2}{*}{ Units } & \multicolumn{5}{|c|}{ Learning objectives for each unit } \\
\hline & 1 & 2 & 3 & 4 & 5 \\
\hline 1. Introduction to digitization & レ & 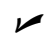 & $x$ & $\mathrm{x}$ & na \\
\hline 2. Citation (and resource) management software & $\boldsymbol{\nu}$ & $\boldsymbol{\nu}$ & $\boldsymbol{\nu}$ & $x$ & $x$ \\
\hline 3. Metadata & レ & $\boldsymbol{\swarrow}$ & $x$ & レ & na \\
\hline 4. Requirements gathering & レ & $\swarrow$ & $x$ & レ & na \\
\hline 5. Project charter and ground rules & na & na & na & na & na \\
\hline 6. CSS, HTML, and how the internet works & $\boldsymbol{\nu}$ & $\boldsymbol{\nu}$ & $\boldsymbol{\nu}$ & $\boldsymbol{レ}$ & na \\
\hline 7. Using WordPress I & レ & $\boldsymbol{\nu}$ & レ & $x$ & $x$ \\
\hline
\end{tabular}

Notes: $\boldsymbol{W}$, indicates that participants mastered the learning objective; $\times$, indicates areas where learning objectives have not yet achieved; $\mathrm{n} / \mathrm{a}$, indicates that there were mo training units

Re-skilling for the digital humanities

213

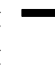


LM

36,3

\section{$214 \quad$ References}

Auckland, M. (2012), Reskilling for Research, Research Libraries UK, London.

Birchinall, L. (2013), "Case study of trainee teachers' responses to the impact of engagement and motivation in learning through a model of cross-cultural context-based learning: "keeping fit and healthy", Curriculum Journal, Vol. 24 No. 1, pp. 27-49.

Dempsey, L. (2013), "Three challenges: engaging, rightscaling, and innovating", Lorcan Dempsey's Weblog, available at: http://orweblog.oclc.org/archives/002213.html (accessed July 17, 2013).

Falchikov, N. (2007), "The place of peers in learning and assessment", in Boud, D. and Falchikov, N. (Eds), Rethinking Assessment in Higher Education: Learning for the Longer Term, Routledge, London, pp. 128-143.

Gutsche, B. (2010), “Coping with continual motion”, Library Journal, Vol. 135 No. 4, pp. 28-31.

Neal, J.G. (2011), "Prospects for systemic change across academic libraries", EDUCAUSE Review, Vol. 46 No. 2, pp. 10-11.

Sambell, K., McDowell, L. and Sambell, A. (2006), "Supporting diverse students: developing learner autonomy via assessment", in Bryan, C. and Glegg, K. (Eds), Innovative Assessment in Higher Education, Routledge, London, pp. 158-168.

Schaufeli, W.B., Bakker, A.B. and Salanova, M. (2006), "The measurement of work engagement with a short questionnaire: a cross-national study", Educational and Psychological Measurement, Vol. 66 No. 4, pp. 701-716.

Schonfeld, R.C. and Rutner, J. (2012), Supporting the Changing Research Practices of Historians, Ithaka S + R, New York, NY.

Williams, P. (2008), "Assessing context-based learning: not only rigorous but also relevant", Assessment \& Evaluation in Higher Education, Vol. 33 No. 4, pp. 395-408.

\section{Web references}

http://library.columbia.edu/dhc.html; http://library.columbia.edu/dsc.html; http://library. columbia.edu/dssc.html; http://library.columbia.edu/music/music_lab.html for more information about the Digital Humanities Center, the Digital Science Center, the Digital Social Science Center, and the Digital Music Lab respectively

http://3dprint.cul.columbia.edu for more information about the 3D printing pilot at the Digital Science Center

www.developinglibrarian.org for more information about the Morningside Heights digital project www.developinglibrarian.org/syllabus/ for an outline of the Developing Librarian Project syllabus

\section{Corresponding author}

Nisa Bakkalbasi can be contacted at: nisa.bakkalbasi@columbia.edu

For instructions on how to order reprints of this article, please visit our website:

www.emeraldgrouppublishing.com/licensing/reprints.htm

Or contact us for further details: permissions@emeraldinsight.com 